\title{
Fatal poisoning and other health hazards connected with industrial fishing
}

\author{
J. B. DALGAARD, F. DENCKER, B. FALLENTIN, P. HANSEN, \\ B. KAEMPE, J. STEENSBERG, ${ }^{1}$ and P. WILHARDT \\ National Health Service of Denmark, Institute of Forensic Medicine, University of Århus, \\ State Institute of Industrial Hygiene, Gentofte, and Technological Laboratory, Ministry of \\ Fisheries, Lyngby, Denmark
}

\begin{abstract}
Dalgaard, J. B., Dencker, F., Fallentin, B., Hansen, P., Kaempe, B., Steensberg, J., and Wilhardt, P. (1972). Brit. J. industr. Med., 29, 307-316. Fatal poisoning and other health hazards connected with industrial fishing. The literature about death and health problems related to work - with fish for industrial use is reviewed. Three fatal cases and several instances of unconsciousness or cases of fainting are reported. An investigation was carried out into the composition of the air in the holds and forecastles of Danish industrial-fishing cutters on their arrival at port. The laboratory procedures are described, and the results are reported. In several instances the low concentrations of oxygen and/or high concentrations of carbon dioxide and hydrogen sulphide found were considered to be hazardous to life. The fatalities and sudden loss of consciousness in the reported cases are ascribed to these changes, hypoxia and hypercapnia being the most important causes. The risk of poisoning seems to be greatest during the landing of trash-fish and in fish-meal plants. Persons under the influence of alcohol may, for one reason or another, be particularly susceptible.

The most important preventive measure is improvement of the quality of the raw material which would also reduce the nuisance from smell. Two safety belts with ropes should be provided in the vessels and close to the pits in the fish-meal plants. Fishermen should leave the vessel after arrival in port and not return until after unloading has been completed. During unloading and in the factories, effective mechanical ventilation is essential. Apparatus to monitor the concentrations of oxygen, carbon dioxide, hydrogen sulphide, and ammonia should be available in the fishing ports, and cases of accident, including mere 'faintings', should be subjected to prompt medical and technical investigation.

From the occupational medical aspect, fishermen are in a less satisfactory situation than workers on shore. An occupational health service, including pre-employment and periodic examinations of personnel and working conditions, is recommended.
\end{abstract}

\section{Introduction and review of the literature}

The fish-meal industry of several countries has expanded greatly since the second world war. This involves certain occupational health hazards. Particular attention should be paid to work with trash-

1Requests for reprints to: Jens Steensberg, M.D., Chief |Medical Officer, Office of Environmental Protection, 45 Store Kongensgade, DK 1264 Copenhagen K, Denmark. fish which may cause ocular and other diseases, loss of consciousness, and even death among fishermen, holdsmen, and workers in fish-meal plants. Furthermore, the landing and preparation of trash-fish are often accompanied by a strong smell, which is a serious nuisance to the local population.

In Great Britain it was noticed in the 1950s that the holds of trawlers returning from distant waters could be dangerous for fishermen and holdsmen, even with consumer fish (Torry Research Station, 
1967). Present conditions are much better, but no recent British investigations into the subject are on record.

In Holland, some workers became ill while landing trash-fish, but no serious morbidity has been reported in relation to such work (Ministerie van Sociale Zaken en Volksgezondheid, 1967).

In the 1950s industrial fishing made considerable progress in the German Federal Republic. Here, as elsewhere, the smell from fish-meal factories has been extremely unpleasant for the local population. Further, several cases of eye disease, followed by blindness in a few instances, were recorded among workers unloading industrial-fishing vessels (Friemann, Overhoff, and Wolter, 1959), and episodes of loss of consciousness have also been reported. In recent years the size of the problem seems to have diminished, probably owing to a decline in industrial fishing, due, among other things, to action taken by the health authorities in connection with the troublesome smells.

Norway carries on extensive fishing operations in European waters, but few attacks of illness have been recorded within recent years. Loss of consciousness occurred among unloading workers in 1968 and 1969. The Norwegian Shipping Department and the Norwegian Employment Supervision have therefore issued safety regulations concerning work in the holds of fishing vessels (Statens Arbeidstilsyn, 1969).

In recent years eye diseases, skin eruptions, and loss of consciousness have also been reported from Chile among people working with fish for industrial use, and five deaths due to such poisoning have been reported (Oyanguren et al., 1971). These events prompted the Fisheries Development Institute of Chile to undertake experimental studies into the production of poisonous gases during decomposition of fish (Reposi, 1968).

In Florida in 1968 five deaths were reported in the hold of an industrial-fishing vessel and were ascribed to the inhalation of hydrogen sulphide produced in the wash water of the fish (U.S. Department of the Interior, 1970).

In a recent accident in Japan, a labourer in a fish-meal factory was found lifeless at the bottom of a fish pit in which was stored fish offal, some of which was putrid. Fellow labourers jumped into the pit to pull him out but were immediately overcome. Six deaths resulted (Mielow, 1971).

International organizations have studied the problem of industrial hygiene within the fishing industry. The International Labour Organization (ILO), the Food and Agriculture Organization of the United Nations (FAO), and the Inter-Governmental Maritime Consultative Organization (IMCO) have agreed certain rules for the safety and health of fishing skippers and their crews (ILO/FAO/IMCO,
1968). Although these rules do not apply exclusively to industrial fishing, they contain several regulations contributing to the prevention of serious accidents in connection with such fishing.

In Denmark the fish-meal industry has expanded since 1966 (Fig. 1). Three deaths have recently been investigated, and several instances of illness and fainting have been recorded, all in relation to the transportation and handling of trash-fish for industrial use. They form the basis for the following report, which also contains the results of investigations of the composition of air in the holds and forecastles of industrial-fishing vessels.

\section{Case reports}

Death from gas poisoning/anoxia on trash-fish cutters Case 1 On 1 September 1966 the 52-year-old second hand on board a 47 ton wooden cutter of Esbjerg was found lifeless at the bottom of the hold at sea. He had been in perfect health and had just entered the hold to shovel ice and fix hold-beams for the next haul. Ten minutes later he was found in a sitting position at the bottom of the hold. He did not react. The skipper descended and fastened a rope round the victim's waist but became unwell himself and was hardly able to get up. The lifeless man was brought up by means of a rope but was dead.

When the cutter arrived at Esbjerg 19 hours later, the cargo hatch was closed until air samples had been withdrawn after two hours and analysed by means of an Orsats apparatus. Blotting paper soaked in lead acetate became black before it had been passed $50 \mathrm{~cm}$ into the hold, suggesting a high concentration of hydrogen sulphide $\left(\mathrm{H}_{2} \mathrm{~S}\right)$ in the air (Fig. 2). Air samples from the middle and bottom of the hold showed oxygen concentrations of 16 and $12 \%$, respectively, and carbon dioxide concentrations of 20 and $22 \%$, respectively.

At necropsy at the Institute of Forensic Medicine, Aarhus, livid stains on the powerfully built man were extensive and strikingly dark, and the blood was mainly liquid and dark. There were no signs of violence or illness. The organs were congested and fairly dark, especially the lungs, but no green discoloration was seen in the brain. Chemical and spectroscopic analyses for carbon monoxide were negative. Histology of the organs showed nothing abnormal.

The cause of death was stated to be suffocation due to hypoxia. It was concluded that fermentation of the fish had induced the evolution of gases, including large amounts of carbon dioxide, which had displaced the fresh air. The presence of further poisonous gases could not be excluded. The manner of death was ruled to be an accident, and further sampling of the air from the holds of trash-fishing cutters was recommended.

Case 2 On 9 August 1968 a 19-year-old fisherman was found dead on board a 45 ton wooden cutter moored in Skagen harbour. He had been 'on the spree' with another fisherman the night before. They returned by taxi at about 3 a.m. rather drunk and descended into the cabin. Owing to the smell and heat, however, his comrade 


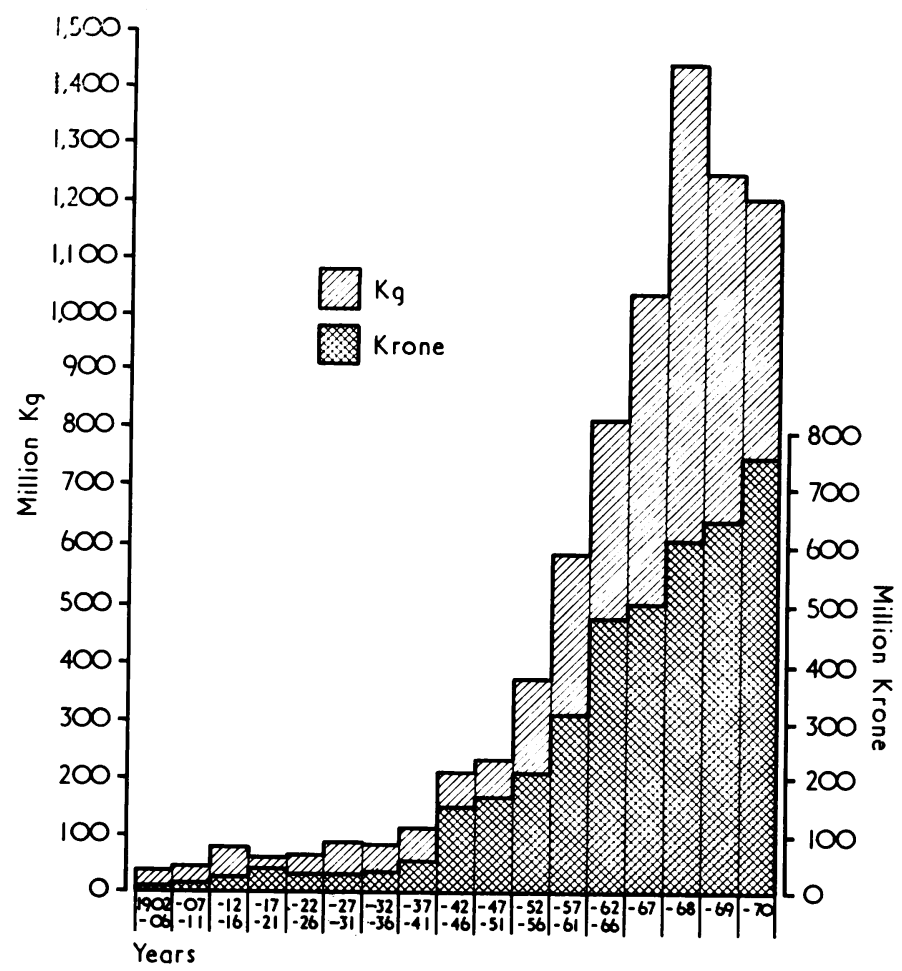

FIG. 1. In Denmark catches of fish have increased greatly during this century. The increases during the 1950 s and 1960 s led to the establishment of a fish-meal industry.

FIG. 2. Effect of storage time and temperature on emission of hydrogen sulphide from whole sand-eel. The hydrogen sulphide was measured by Dräger tube on a 1-litre sample of air enclosed in a plastic pouch with $500 \mathrm{~g}$ of sand-eel which were broken in the pouch 10 minutes before measurement. This simulated the breakage of fish during unloading operations. A rapid and pronounced emission of hydrogen sulphide is seen when the fish has been stored at $+9^{\circ}$ or $+12^{\circ} \mathrm{C}$. Emission is low or nil at storage temperatures of $+3^{\circ}$ or $0^{\circ} \mathrm{C}$.

Fig. 1

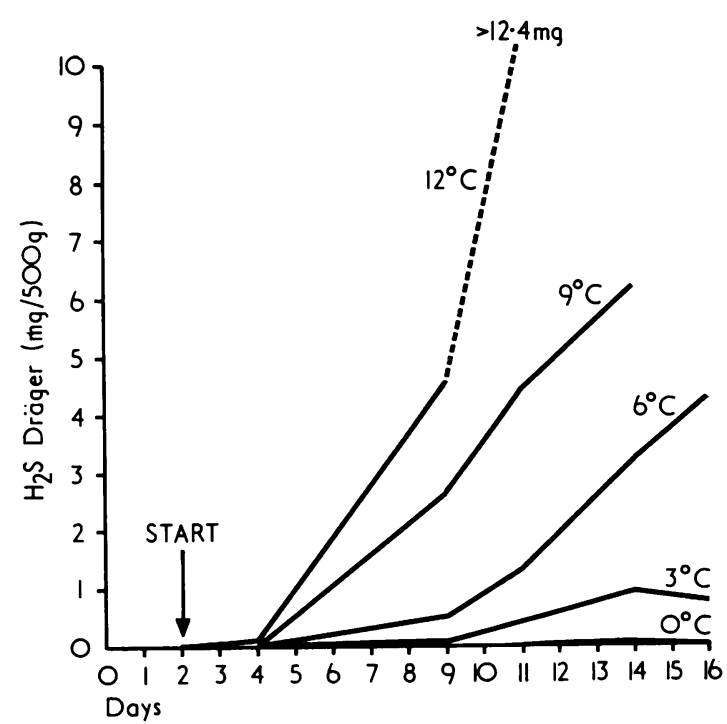

Fig. 2 moved to the wheelhouse to sleep there. There was no evidence to suggest that the deceased man had been suffering from any grave disease or had taken any drugs. A third fisherman had come in at 11.30 p.m. and slept in the same cabin until about 4 a.m. when he woke up troubled by the heat and smell and a sensation of difficulty in breathing. He left the boat about 5 a.m. At about 11.30 a.m. the man in the wheelhouse descended and found his friend lifeless in the cabin. He was immediately brought to the deck and given artificial respiration but was dead.

The first sweep of the seine had been hauled on board on 4 August and fishing had continued until 7 August, when the hold was full of trash-fish ('calypso') to which formaldehyde had been added. The boat had arrived at Skagen on 8 August at 4 a.m., but unloading was postponed owing to pressure of work. It was a very hot day with no wind and the cargo had begun to putrefy. There was a double wooden bulkhead between the hold and the forecastle which was aired through the totally open skylight and air ducting. Further, the door of the cabin had been open all the time. Unfortunately, equipment for adequate collection of gas samples was not available, but samples of the decomposing fish from the hold had been secured by the police in a solid plastic box. 


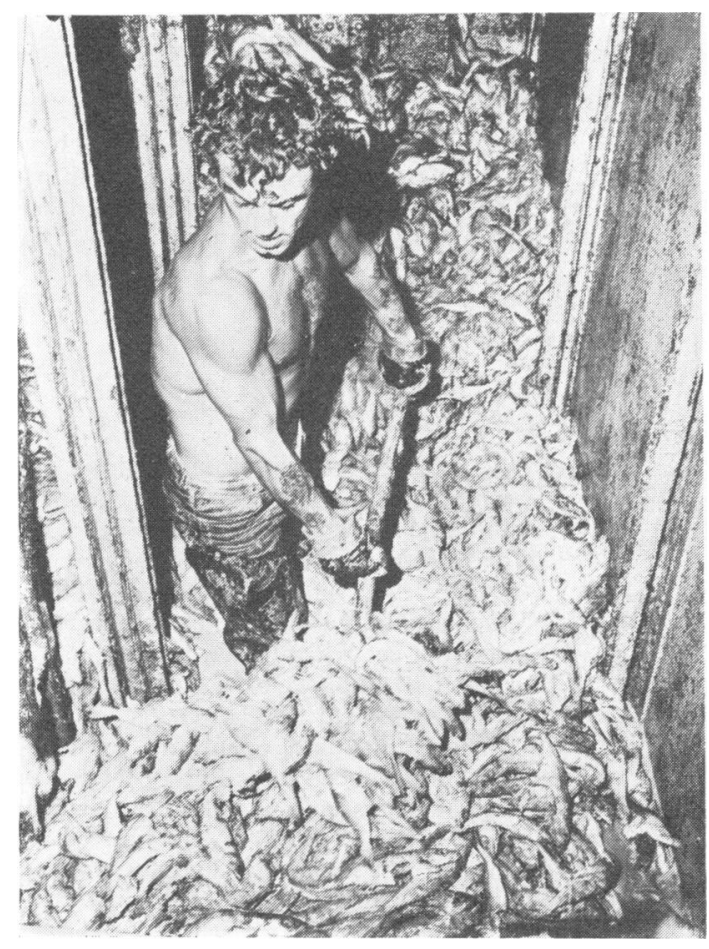

FIG. 3. Working conditions in the cargo-room. Standing alone, shovelling putrefied fish for hours in a temperature of $25^{\circ} \mathrm{C}$ with an incredible stench is hard work-and dangerous-but it is well paid.

The air in this had a very unpleasant smell and contained 'an enormously increased amount of carbon dioxide'.

At necropsy this medium-sized man had dark blue livid stains, and the whole corpse was darker than normal with a peculiar unpleasant smell. The conjunctivae were congested, and the mucosae of the air passages were flushed. A few petechial haemorrhages were found on the pericardium. Excessive amounts of blood and fluid were present in the lungs. The brain showed no green tint. No signs of violence or illness were found. Histology of the organs showed nothing abnormal.

The concentrations of alcohol in the blood and urine withdrawn during necropsy were $1.95 \%$ (ADH method) and $1.01 \%$ (gas chromatography) respectively. It was concluded that the cause of death was most likely hypoxia together with intoxication with carbon dioxide and alcohol.

Case 3 On 2 August 1971 a 39-year-old fisherman was found dead in his cabin on board a wooden fishing cutter (55 tons gross) in Esbjerg harbour. The cargo consisted of 67 tons of sperling, and the cutter had been lying at the quay for 30 hours on a rather hot day. The smell was extraordinarily bad and strong. The holdsmen had started their work at 6 a.m. and then noticed that the light was on in the cabin. At 9.45 a.m. a holdsman found the fisherman half sitting, half lying on his berth with his clothes on, obviously dead as he was already stiff and cold.

The deceased had enjoyed perfect health and had been 'on the spree' on the previous night and consumed at least 15 beers but did not appear to be very drunk when he returned to the boat by taxi at about midnight.

At necropsy the body had a strong smell of fish. The skin was fairly dark, especially the face, with a slight green tint. Necropsy showed slight cerebral and very pronounced pulmonary oedema but no evidence of violence or disease. The brain showed no green tint, and no smell of $\mathrm{H}_{2} \mathrm{~S}$ was noticed in the lungs. The alcohol concentration in the blood, estimated by the $\mathrm{ADH}$ method, was $0.74 \%$, and in the urine (gas chromatography) $1.0 \%$. No carbon monoxide was found in the blood. Histology of the organs showed nothing abnormal. It was concluded that the cause of death was a combination of anoxia and acute poisoning, presumably with $\mathrm{CO}_{2}$ and alcohol.

It was later found that foul-smelling water from the decomposing fish cargo had penetrated from the hold to beneath the floor of the cabin. The deceased had been warned against sleeping there when the cutter was at the quay with decomposed trash-fish on board.

\section{Non-fatal illness during work with trash-fish}

In the two main Danish fishing ports of Esbjerg and Skagen, fainting fits have sometimes been almost daily occurrences among holdsmen unloading trashfish. Such episodes are generally minimized because the victims soon recover in fresh air. In other cases, however, where consciousness has not returned immediately, the victims have been taken to hospital. Doctors, particularly in Esbjerg, have reported several such cases where patients had lost consciousness while unloading industrial-fishing vessels, while staying in the forecastles of vessels, or while working in fish-meal factories. In some instances the patient's respiration and blood circulation had been arrested and it was only by chance that he had survived. Such serious cases, even if not fatal, involve a risk of permanent brain damage.

Four typical cases of unconsciousness causing admission to hospital are briefly reported:

Case 4 On 25 June 1968 a 26-year-old holdsman fainted in the hold while at work unloading an industrial-fishing vessel (Figs. 3 and 4) in the port of Esbjerg. In falling, his right knee had been hurt by a grab of the unloader. He was admitted to the medical department of the County Hospital, Esbjerg. On arrival he was already awake and fully conscious. He was transferred to the surgical ward and treated for a contusion of the right knee and discharged seven days later with the diagnoses of poisoning due to vapour and a fracture of the medial condyle of the right femur.

Case 5 On 4 August 1968 a 44-year-old Finnish sailor was found unconscious in the forecastle of a 39 ton wooden fishing vessel in the port of Esbjerg. He had been 'on the spree' with another fisherman for two days and 


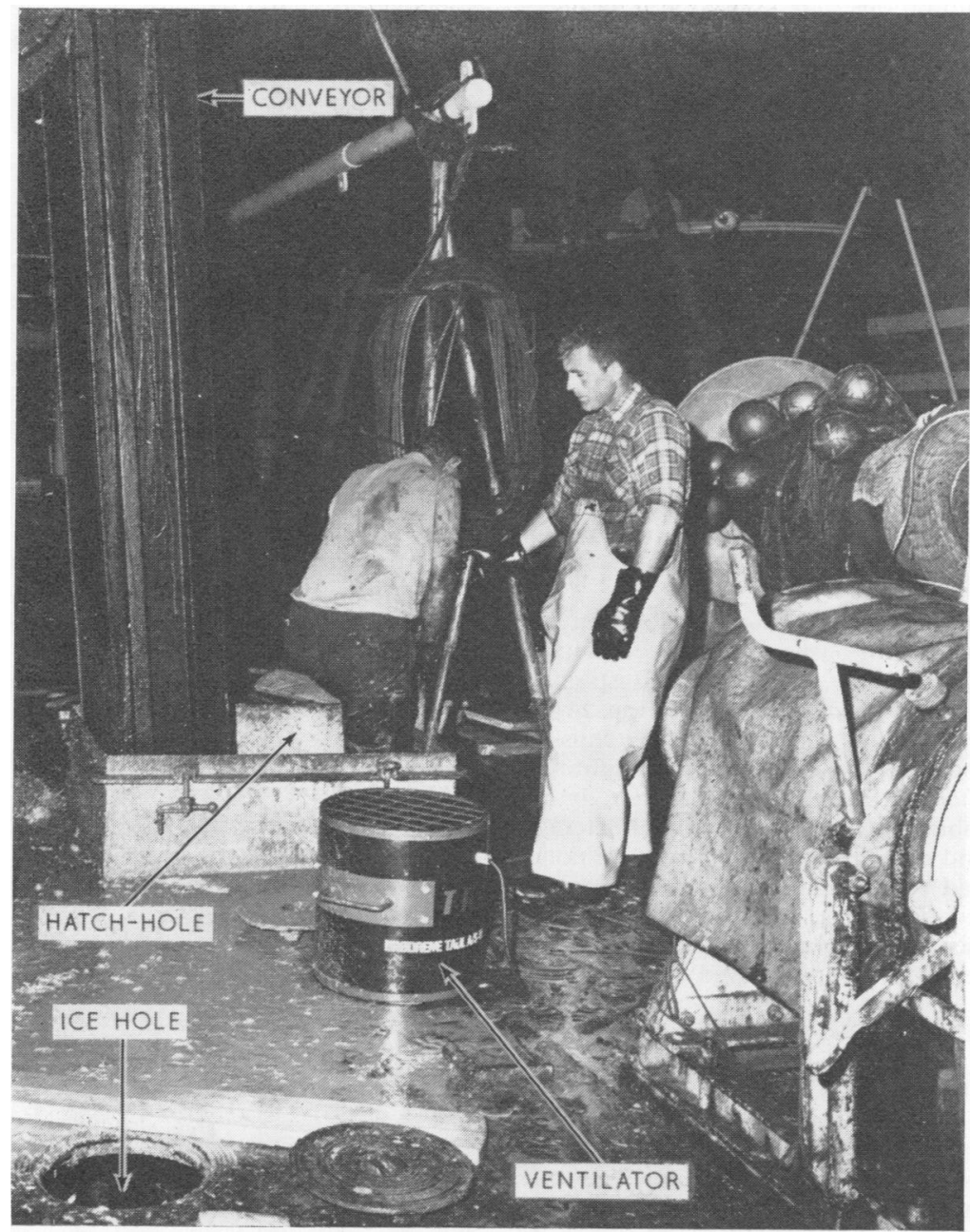

FIG. 4. Working conditions during the unloading of trash-fish. The mechanical conveyor has been put down through the hatch-hole. A powerful electric ventilator is blowing fresh air down through an ice-hole; another open ice-hole is seen in the lower left corner. The first holdsman is about to descend through the hatch-hole to the cargo-room to supply fish to the conveyor. He wears no safety belt with snaphooks or safety rope.

they were both rather drunk when they boarded the cutter and descended to the forecastle to have supper. After 15 to 20 minutes the Finn fell ill and became unconscious. He was taken to the County Hospital, Esbjerg, where cyanosis of the face, a slightly drooping left corner of the mouth, and sluggish reflexes of the right leg were recorded. He regained consciousness after 15 minutes, and the neurological signs subsided and had disappeared completely by the next day. The patient was discharged symptom free four days later with a diagnosis of 'poisoning due to vapour'.

Case 6 On 16 July 1968 a 49-year-old labourer was found apparently lifeless at the bottom of the fish-pit of a fish-meal factory at Esbjerg. He was brought up and given artificial respiration, and spontaneous respiration started after some minutes. On arrival at the County Hospital he was still unconscious with rattling respiration and cyanosis. The pupils were dilated and did not react to light. Bilateral positive Babinski reflexes and a blood pressure of $260 / 140 \mathrm{~mm} \mathrm{Hg}$ were recorded. The patient was very restless and was given sedatives by injection. After 24 hours he regained consciousness and the disorders of the reflexes had declined. Lumbar puncture failed. Ophthalmological examination showed no abnormality. A chest $x$-ray on admission was normal, 
but the next day infiltrations were noticed in both lungs, progressing on the following day. An $x$-ray of the skull showed nothing abnormal. The patient took his own discharge on the third day against medical advice. He was given antibiotics and remained feverish for several days after discharge. The final diagnosis was poisoning by an (unknown) gas. The patient had never before been seriously ill. He was alleged to have hurt his head a week before this episode and complained of headache for three days, but he had not felt unwell thereafter.

The fainting fit had occurred in the raw material store room in a low intermediate passage between the $3 \mathrm{~m}$ deep pits into which wagons empty the raw material of trashfish. On the day concerned, the plant had been out of action for 7 hours. There was a large amount of fish, mainly haddock, from the previous day, which fermented and bubbled from decomposition. Although the use of available portable ventilators had been ordered whenever the workers were about to descend into the pits, none of the fans was working at the time of the accident.

Case 7 On 11 August 1969 a 59-year-old labourer, who had previously been healthy, was found unconscious in the pit of a fish-meal factory at Skagen. Respiration having ceased, artificial respiration was given in the ambulance on the way to Skagen Hospital. On admission the patient was unconscious with very slow respiration, which improved after aspiration of secretions and oxygen treatment. The Babinski reflex was positive bilaterally, extensor spasms and excessive motor unrest were noted, and the patient had to be strapped to his bed despite treatment with sedatives. The next day he was fully conscious and orientated though unable to remember what had happened. He was discharged after two days in hospital.

The raw material consisted of small herring, a fish particularly liable to decompose rapidly, and was in a state of extreme fermentation after a particularly hot weekend. The victim had descended into the deep passage between the pits containing the fermented fish and was found unconscious five minutes later. A fellow labourer, who tried to help him, also became unwell and was on the point of fainting, but others lifted the unconscious man out of the pit. It was later confirmed that ventilation was inadequate. Before the accident another labourer working in the same place had complained of smarting eyes and had had to sit down and rest several times.

The State Institute of Industrial Hygiene examined the plant 13 hours after the accident. By this time, however, the plant had been ventilated and the concentrations of oxygen, carbon dioxide, and hydrogen sulphide were within acceptable limits.

\section{Eye complaints}

The general practitioners of Esbjerg and Skagen are often consulted by patients complaining of eye symptoms after working with trash-fish either during fishing, when landing fish, or when working in the fish-meal plants. In July and August 1968 particularly, many such patients presented, and on one particular day seven patients had to be treated for conjunctivitis. The symptoms were reminiscent of those seen on exposure to tear gas and generally subsided after the patients had rested for a few days with the eyes protected against the light. No instance of persistent visual defect has been recorded.

\section{Other complaints}

In the summer of 1968, several Skagen workers who had been unloading trash-fish complained of respiratory troubles, nausea, dizziness, and eye complaints occurring during work, and many complained of a rash, especially on the arms, which they attributed to the use of formaldehyde as a preservative. When the holdsmen came up to get fresh air they were often seen to reel and had to sit down to save themselves from falling.

In Esbjerg the holdsmen frequently have to take a week's 'holiday' owing to 'indisposition'. Poisoning due to work with trash-fish might occur more frequently than the relatively few notified cases suggest.

\section{Malodour}

In Esbjerg, Skagen, and elsewhere, the landing, transportation in open lorries, and preparation of trash-fish cause considerable inconvenience from malodour, which is particularly evident in hot weather. The local health authorities have ordered measures to prevent this under the provisions of the local sanitary regulations. However, the inconvenience from malodour and the risks of poisoning are, of course, closely connected and depend primarily upon the condition of the fish when landed.

\section{Present study}

\section{Air composition in holds and forecastles}

Because of the attacks of illness and the first death (case 1), the authorities in the autumn of 1968 discussed with representatives of the fishermen, holdsmen, and fish-meal manufacturers the measures which might be taken to prevent accidents from work with trash-fish. It was decided to perform a preliminary investigation of the composition of air in the holds and forecastles of trash-fishing cutters to obtain reliable figures for preventive measures. The investigations were organized by the National Health Service of Denmark, the State Institute of Industrial Hygiene (SIFA), and the Institute of Forensic Medicine, Århus.

As the daily routine of unloading industrialfishing cutters does not allow systematic withdrawal of a series of air samples from the vessels, the investigation had to be based on random sampling from the vessels which were supposed to involve the greatest risk to fishermen and holdsmen. First, samples had to be withdrawn immediately after opening the hatches, or at least before ventilators 
had been set up and the unloading begun. Next, as soon as possible after the ventilators had been started, another series of air samples was taken, to monitor the efficiency of the ventilators.

\section{Laboratory analyses}

The pilot study further resulted in the selection of the Dräger gas detector for measuring carbon dioxide $\left(\mathrm{CO}_{2}\right)$, oxygen $\left(\mathrm{O}_{2}\right)$, hydrogen sulphide $\left(\mathrm{H}_{2} \mathrm{~S}\right)$, ammonia $\left(\mathrm{NH}_{3}\right)$, and formaldehyde (HCHO). The indicator tubing was as follows: $\mathrm{CO}_{2} 1 \%$ or $\mathrm{CO}_{2} 5 \% / \mathrm{A}, \mathrm{O}_{2} 5 \% / \mathrm{A}, \mathrm{H}_{2} \mathrm{~S} 1 / \mathrm{B}$ or $\mathrm{H}_{2} \mathrm{~S} \mathrm{100/a}, \mathrm{NH}_{3} 25 / \mathrm{a}$, and $\mathrm{HCHO} 0.002$. The accuracy of the indicator tubes employed was tested at SIFA and found to be within the values stated by the manufacturer (Drägerwerk, Lübeck).

Carbon dioxide, amines (trimethylamine $\left(\mathrm{CH}_{3}\right)_{3} \mathrm{~N}$, diethylamine $\left(\mathrm{C}_{2} \mathrm{H}_{5}\right)_{2} \mathrm{NH}$, and n-butylamine $\left(\mathrm{C}_{4} \mathrm{H}_{9} \mathrm{NH}_{2}\right)$, and methane were measured in air samples withdrawn for subsequent gas chromatography to be carried out by SIFA. The air samples were withdrawn in $300-\mathrm{ml}$ glass gas pipettes provided with two taps. About one litre of air was drawn into the gas pipette by means of a small battery-driven pump. In the laboratory 2-ml samples were withdrawn from the gas pipettes through a serum cap by means of an air-tight Hamilton's syringe and thereafter injected direct into a Varian Aerograph 1520 gas chromatograph mounted with both flame ionization detectors (FID) and thermal conductivity detectors (TCD) (Fallentin, 1965).

Amines (Sze, Borke, and Ottenstein, 1963) $2 \mathrm{~m} \times \frac{1}{8}$ in column with $5 \%$ TEP (tetra-ethylene pentamine) + $15 \%$ DIG (diglycerol) on Chromosorb W (60/80 mesh). Column temp. $60^{\circ} \mathrm{C}$ FID $\left(30 \mathrm{ml} \mathrm{H}_{2} / \mathrm{min}\right)$. Carrier gas: $30 \mathrm{ml} \mathrm{N} / \mathrm{min}$.
$\mathrm{CO}_{2} 2 \mathrm{~m} \times \frac{1}{8}$ in. column with silica gel (60/120 mesh) Column temp. $85^{\circ} \mathrm{C} \mathrm{TCD}$. Carrier gas: $30 \mathrm{ml} \mathrm{He} / \mathrm{min}$.

$\mathrm{CH}_{4} 5 \times \frac{1}{8}$ in. column with Mol. Sieve $5 \mathrm{~A}$ (30/60 mesh). Column temp. $50^{\circ} \mathrm{C}$ FID $\left(30 \mathrm{ml} \mathrm{H}_{2} / \mathrm{min}\right)$. Carrier gas: $30 \mathrm{ml} \mathrm{N} / \mathrm{min}$.

The quantitative estimation was performed by measuring ceilings and comparing with standard gas mixtures.

\section{Results}

Holds

On 12 and 13 August 1969, after a fairly long period of hot weather, the State Institute of Industrial Hygiene undertook an investigation of seven cutters (nos. 1 to 7) in the port of Esbjerg. The results of analyses of air samples withdrawn immediately after opening the hatches, or just before starting the ventilators, are given in the Table. The cutters are numbered in order of rising carbon dioxide concentrations in air. In three cutters the oxygen concentration was dangerously low.

The investigations in the port of Skagen (cutters 8 to 13) were carried out by the Institute of Forensic Medicine, Århus, from 17 to 19 August 1969, when it was still rather hot. Seven cutters were examined, but one has been excluded because the ventilators had been started before the first samples were withdrawn. In four of these cutters the oxygen concentrations were dangerously low.

Besides the analyses presented in the Table, the concentrations of methane $\left(\mathrm{CH}_{4}\right)$ were also measured,

TABLE

Gas Analyses in Holds of 13 Industrial-fishing Cutters immediately AfTer OPENINg Hatches IN PORT

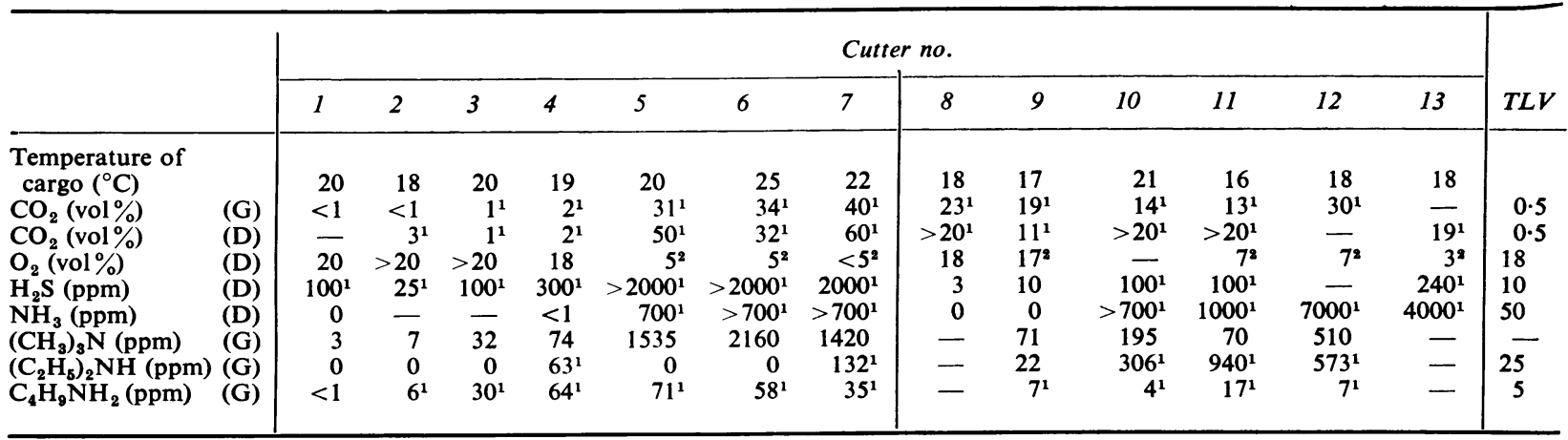

The cutters ranged between 50 and 171 tons gross. The cargo was haddock in all cases, except in No. 6, which carried herring; cutter No. 1 carried both. The preservation method was icing in Nos. 1 and 2, formaldehyde in Nos. 3-7, 9, and 11, and both icing and formaldehyde in Nos. 8, 10, 12, and 13. The cutters had been at sea for 2-9 days (mostly 4-7 days) and had been waiting for up to 44 hours in port before leasing.

$\mathbf{G}=$ analysis by gas chromatography.

$\mathrm{D}=$ analysis by Dräger gas detector.

${ }^{1}$ Exceeding TLV (Threshold Limit Value, Amer. Conf. Government. Indust. Hyg., 1969).

${ }^{2}$ Below minimum oxygen content, according to TLV. 
but in all the cutters they were considerably below explosion level ( 5 vol. \%). In only two cutters (both at Esbjerg) could measurable concentrations of formaldehyde be detected in the air, in both cases below the threshold limit value (TLV) for HCHO (5 ppm).

The Table shows fair agreement between the carbon dioxide concentrations measured with Dräger's apparatus and those measured by gas chromatography. Differences may be due, among other things, to air samples being withdrawn at different times. In nearly all the cutters the hydrogen sulphide concentration was above the TLV. It is worth noting that the indicator tubes for measuring ammonia partially include the methylamines demonstrated by gas chromatography. No TLV has been established for trimethylamine, but the TLV was in many cases exceeded for the other two amines. Moreover, in several samples there were signs of other non-identified higher amines.

Further study of the findings revealed no obvious relation between the results of the gas analyses and either type of fish in the cargo (haddock/herring), the method of preservation (ice/formaldehyde), the length of time at sea or in harbour, or the temperature of the cargo registered in port. But that might be attributable in part to the relatively small number of observations.

The gas concentrations in the holds 10 to 15 minutes after the ventilators had been started, and when the first holdsmen descended into the holds, have not been presented in the Table because, during the hectic work of unloading the vessel, it was impossible to take measurements at definite time intervals. Those measurements showed that powerful ventilators blowing fresh air through the main hatch to the hold (and through the ice-shutters) change the composition of the air in the course of 10 to 15 minutes so that working in the hold for short periods no longer involves any risk.

However, more recent analyses of air from the Skagen cutters have shown that, in certain cases, a critical phase occurs when the mechanical conveyor has begun to unload fish from the room immediately below the cargo hatch. A moment later oxygen may be completely displaced, presumably by the large volumes of poisonous gases streaming out from the cargo into the hole produced by the conveyor. This phenomenon was plainly demonstrated in cutter no. 8 , from which the results of the first analyses after opening the hatch were not particularly alarming. Another series of air samples were taken about one hour after the mechanical conveyor had begun to work, but before the ventilators had been started. At this time the air in the hold was found to contain no measurable amount of $\mathrm{O}_{2}$, while $\mathrm{H}_{2} \mathrm{~S}, \mathrm{NH}_{3}$, $\left(\mathrm{CH}_{3}\right)_{3} \mathrm{~N},\left(\mathrm{C}_{2} \mathrm{H}_{5}\right)_{2} \mathrm{NH}$, and $\mathrm{C}_{4} \mathrm{H}_{9} \mathrm{NH}_{2}$ were present in concentrations of $600 \mathrm{ppm}, 800 \mathrm{ppm}, 59 \mathrm{ppm}$,
$1690 \mathrm{ppm}$, and $6 \mathrm{ppm}$ respectively. Obviously a holdsman who descends into the hold during this phase of the work will die immediately through lack of oxygen, apart from the combined toxic effect of the gases.

\section{Forecastles}

In the Esbjerg cutters examined, all the cabins of the forecastles had been aired for not less than 24 hours at the time of the examination. Hence, measurements of air were made from one forecastle only (cutter no. 6) where the skylight had been open for about 24 hours. The only remarkable measurement was that the hydrogen sulphide concentration was $15 \mathrm{ppm}$.

In the Skagen study, air samples were analysed from the forecastles of five cutters and were found to be satisfactory in four. In the fifth (cutter no. 10) both skylight and door were kept open. Because of the strong smell the skipper had forbidden the crew to stay in the forecastle. Two consecutive measurements with the Dräger apparatus revealed a complete absence of oxygen in the air. At the same time there was a reading of $16 \mathrm{vol} \% \mathrm{CO}_{2}, 600 \mathrm{ppm} \mathrm{H}_{2} \mathrm{~S}$, and $7000 \mathrm{ppm} \mathrm{NH}$. In this case even a brief stay in the cabin would presumably have proved fatal due to lack of oxygen.

\section{Discussion and conclusions}

This paper does not set out to present a complete epidemiological study of mortality and morbidity in persons working with fish for industrial use. The fatal cases reported in the literature, and the three deaths reported here, however, give an indication of the severity of the problem. As the 'population at risk' is very difficult to define, we have made no attempt to estimate the incidence or prevalence. As to morbidity, we have received some information from local general practitioners and hospitals, but it is not complete. Non-fatal cases of poisoning might be supposed to occur more frequently than the relatively few notified cases suggest. Even loss of consciousness has not always been notified as the people at risk usually do not understand that the margin between cases of 'mere fainting' and a fatal issue is very narrow. Our knowledge of the incidence of eye complaints is also rather deficient. However, our impression is that no instance of keratitis followed by a permanent visual defect (Friemann et al., 1959) has occurred in this country. Many fishermen and others working with trash-fish seem to be troubled by skin eruptions. Further investigations into this problem may lead to suitable preventive measures.

Cases 2, 3, and 5 suggest that persons under the influence of alcohol are particularly susceptible to the type of poisoning described here (or the circumstances may increase the danger) - as well as to 
several other risks. If this is correct, the risk might be higher in port, before unloading, than at sea, due to the drinking habits following landing after several days or weeks of hard work at sea. The unconscious patients admitted to hospital presented signs and symptoms corresponding to those reported from Chile (Oyanguren et al., 1971). Comparing the symptoms in the fatal cases with the grave neurological symptoms in our cases 5,6 , and 7 , we suggest that it might be chance that we have seen 'only' three deaths due to poisonous gases from trash-fish within the past five years.

Schilling (1966) has stated that legislation in Great Britain protecting the health, safety, and welfare of fishermen compares unfavourably with similar legislation for workers in less dangerous and less exacting jobs. The same is true in Denmark. The importance of 'having a better system of recording and investigating both fatal and non-fatal accidents among crews of fishing vessels' should also be stressed. There is reason to point out the importance of notifying accidents both at sea and on land to the Accident Insurance Department, in conformity with the rules of the Danish Industrial Insurance Act. Only in this manner can the authorities learn enough about the problems and so be in a position to recommend preventive measures.

The responsibility for the occupational medical problems of industrial fishing in Denmark, as in most other countries, is divided between the State Directorate for Ship Inspection and the Labour and Factory Inspection. The two authorities have established collaboration in the work of loading and unloading. It is, however, our impression that those engaged in the fishing industry are in a less satisfactory position from the occupational medical aspect than workers on land. We therefore reiterate Moore's (1969) proposal for the establishment of an occupational health service for trawlermen including compulsory pre-employment and periodic examinations.

As stated previously, our selection of fishing vessels for taking air samples was random and thus allows only limited conclusions. We have not undertaken similar environmental investigations in fishmeal plants, but similar conditions are likely to be demonstrable, as evidenced by both our cases 6 and 7 and studies made in Chile (Oyanguren et al., 1971), and experience in Japan (Mielow, 1971).

Unfortunately, our analyses of air from the forecastles of fishing vessels were not as complete as desired, but the results from cutter no. 10 bear out the high risk involved to those staying in the forecastle in port before the cutter has been unloaded. Our series includes a fatal case (no. 2) and one of loss of consciousness (no. 5) occurring there. In our opinion, the rapid loss of consciousness in both these cases was due to oxygen deficiency combined with a high carbon dioxide concentration.

The Chilean investigators paid particular attention to the high hydrogen sulphide concentration. However, victims of $\mathrm{H}_{2} \mathrm{~S}$-poisoning generally have a characteristic smell of $\mathrm{H}_{2} \mathrm{~S}$, particularly in the lungs, and a characteristic greenish tint of the brain, which we did not find in our cases. This does not exclude the possibility that $\mathrm{H}_{2} \mathrm{~S}$ may play a part in other cases. The high concentrations of amines found may also be dangerous.

Our experience with the Dräger apparatus, including a comparison with the results from the gas chromatograph of the concentrations of carbon dioxide, justifies the recommendation that accidents should be investigated and occasional monitoring performed with the Dräger apparatus alone.

The most important basic measure for the prevention of gassing from trash-fish is to improve the quality of the raw material. The investigations carried out at the Technological Laboratory under the Danish Ministry of Fisheries have already afforded a basis for this (Hansen et al., 1972). Such measures would likewise reduce the unpleasant smell.

A minimum precautionary measure is to require on board all industrial-fishing vessels and in all trash-fish plants two safety-belts with ropes and snaphooks. Such equipment allows a rescuer to descend into the hold or pit with one belt round his waist and the rope fastened to this. He can then fasten the other belt with ropes round the waist of the injured or unconscious person. This conforms to the Code of Safety for Fishermen and Fishing Vessels (ILO/FAO/IMCO, 1968), which mentions that 'a second man should be in attendance'.

Further, fishermen should be instructed to leave the vessel on arrival in port and not to return until the unloading is finished and the vessel thoroughly aired. Effective ventilation by means of mechanical ventilators is required during the unloading and in the factories.

Holdsmen or workers who faint should be examined in the nearest hospital, even if they regain consciousness after a short while. A complete case history should be obtained and an environmental investigation carried out.

\section{Note}

Safety instructions for work with fish designated for fishmeal and similar purposes were issued in 1970 by the Danish Labour and Factory Inspection Directorate and the Danish State Directorate for Ship Inspection. This pamphlet together with an English translation of the text can be obtained on request from the Direktoratet for Arbejdstilsynet, Biblioteket, Upsalagade 20, DK-2100 Copenhagen $\emptyset$, Denmark.

\section{References}

Fallentin, B. (1965). Gaschromatografisk bestemmelse af luftforureninger. Dansk kemi, 46, 133-136. 
Friemann, W., Overhoff, W., and Wolter, J. R. (1959). Augenerkrankungen in der Industriefischerei. Arch. Gewerbepath. Gewerbehyg., 17, 1-56.

ILO/FAO/IMCO (1968). Code of Safety for Fishermen and Fishing Vessels. Part A. Safety and Health Practice for Skippers and Crews. Geneva, Sept. 1968 (Mimeographed).

Mielow, F. (1971). Personal communication.

Ministerie van Sociale Zaken en Volksgezondheid Holland (1967). Personal communication.

Moore, S. R. W. (1969). The mortality and morbidity of deep sea fishermen sailing from Grimsby in one year. Brit. $J$. industr. Med., 26, 25-46.

Oyanguren, H. M., Reposi, J. M., Pagola, A. I., Quezada, M. C., Gonzalez, O. R., Lombardi, J. S., and Bahamonde, M. L. (1971). Poisoning in the fish meal industry. In XVI int. Congr. occup. Hlth, Tokyo, Sept. 1969, pp. 713-715.
Reposi, J. (1968). Estudio preliminar sobre los gases toxicos producidos durante la descomposicion del pescado en la industria de harina. Publnes. Inst. Fom. pesq. Santiago, No. 38, $17 \mathrm{pp}$.

Schilling, R. S. F. (1966). Trawler fishing: an extreme occupation. Proc. roy. Soc. Med., 59, 405-410.

Statens Arbeidstilsyn, Norge (1969). Vernetiltak ved lossing av fisk som råstoff til sildefabrikker. Oslo (mimeographed).

Sze, Y. L., Borke, M. L., and Ottenstein, D. M. (1963). Separation of lower aliphatic amines by gas chromatography. Analyt. Chem. (Wash.), 35, 240-242.

Torry Research Station, Humber Laboratory, Hull (1967). Personal communication.

U.S. Department of the Interior, Fish and Wildlife Service, Bureau of Commercial Fisheries (1970). Personal communication.

Received for publication October 25, 1971. 